\title{
What Future We Do Want: Some Considerations Related to the Emergence of Global Sociology
}

\author{
Oleg N. Yanitsky \\ Institute of Sociology Russian Academy of Sciences, \\ Moscow, Krzhizhanovsckogo St., 24/35, b. 5 \\ oleg.yanitsky@yandex.ru
}

\begin{abstract}
The emergence and development of 'global sociology' advances to the forefront a set of uneasy questions. This article outlines the scope of some questions which, in the author's opinion, should be discussed before and during the coming ISA forum 'The Future We Want: Global Sociology and the Struggle for Better World' which is to be held in Vienna next year. Each notion of this heading as well as the state-of-art in this relatively new and rapidly developing sociological field should be exposed to analysis and critical reflection in order to foster for the production of sociologically relevant knowledge. Some starting points and key questions related to the methodology and theory of the global sociology field are named and discussed. Such basic concepts as 'future', 'better world', 'who are "We"?' as well as the possible types of 'future social order' and how to define a 'social capital' of the desired 'global world' and its environmental dimensions are discussed. In conclusion the author put forward twelve theses which are the necessary requirements which the global sociology should to address and carefully analyze. In the author's view, problem-oriented and activist-oriented comparative researches, interdisciplinary stance and the processes of the emergence of new global actors should be at the top of the research agenda in this field.
\end{abstract}

\section{Keywords}

Better world; global sociology; global world; interdisciplinary approach; local-global and the 'South-North' dichotomies; social order; social movements; struggle.

\section{Academic Discipline And Sub-Disciplines}

Sociology

\section{SUBJECT CLASSIFICATION}

Library of Congress Classification: Subclass HM - Sociology (General)

\section{TYPE (METHOD/APPROACH)}

Literary Analysis; theorization, interdisciplinary approach

\section{Council for Innovative Research}

\section{Peer Review Research Publishing System}

\section{Journal: Journal of Social Sciences Research}

Vol. 9, No.1

jssreditor.cir@gmail.com

www.jssronline.com 


\section{Introduction, preliminary remarks}

The idea of this article has emerged on the crossroads of two streams of thinking: is a model of desirable future of the world is actually exists? And if it is so, in which frames of reference (i.e. concepts, tems, etc.) we, sociologists, should adequately comprehend it? The emergence and development of 'global sociology' advances to the forefront a set of uneasy questions. This article outlines the scope of such questions which, in the author's opinion, should be discussed before and during the coming ISA forum 'The Future We Want: Global Sociology and the Struggle for Better World' which is to be held in Vienna next summer. Of course, I am not capable to embrace all questions related to this issue. Other sociologists will put quite another questions, and moving this way we could finally formulate more relevant set of key questions. I'd like to speculate on the topic in the form of questions and answers with some comments along the line.

The first set of questions directly related to the formula of the above Forum is as follows: First, maybe it would be more correct to speak not on a 'unified model' but about the variety of the 'better worlds' in accordance with the state -of-art in particular countries, regions and sub-continents? Second, one more methodological question is in what way the sociologists will construct a model of the 'Better World': moving top-down or bottom-up? And the third one: Who are these 'We': the global 'society' at large or the sociological community only? Today, the majority of sociologists are clearly realizes that any unified view of the global future is unachievable. One could speak in tems like 'more' and 'less' only (le ss risks and use of teminal weapons, more peace and discussions, etc.). Nevertheless, there are some restrictions which the Nature imposes on humanity: there are limits which it imposes on human activity. The problem here is that these limits are act imm ediately or they are postponed, slightly visible or unintended at all?

Then, the next, even more acute question arises: could the participants of the above Forum to explicate the variety of views on the issue, because it is the necessary step for future discussions and modeling. The more socially and professionally this chorus will be diversified, the more embracing picture we will get. Anyhow, the interdisciplinary and local-global (top-down and bottom-up) approached are necessary $[1 ; 2 ; 3]$. And another urgent problem of the issue: whose ideas and views should be taken into account? As it many times already happened in the human history it would be only those who are recently dominate, economically or politically, be it the groups of interest in social sciences, business or politics? Or, the worst, they will be only those who are the holders of a brute force only? Anyhow, the question 'who are we?' is tightly connected with the necessity of restructuring of existing global social order. But it does not mean that we should wait when this order will be established by some 'others'. There is no way out but to launch the discussion on the abovementioned topics immediately.

\section{Main characteristics of the modern world, political reasons of the emergence of a state of all-embracing risk}

To begin with, this world is highly interconnected and therefore vulnerable, open to injury. Thus, it is simultaneously rather liquid and 'situated', i.e. locally fixed. Then, there are no absolutely safe places on the Earth - there are more or less safe places only. It is the direct result of the transformation of global community into society of 'all-embracing risk' $[4 ; 5 ; 6 ; 7]$ For years, the maintenance of nuclear parity was the mean for the maintenance world peace. But today armed individual and group terrorism coupled with private armies has become as risky as tough political pressure or military operation of the states or their coalitions. Currently, the process of violation of global social order established after the WWII has now reached its peak. To my mind, this risky instability is the result of this world passing through the phase 'in-between', i.e. between less and less workable old social order and unpredictable process of the emergence of a new one. This transition cannot be peaceful, because the forces involved have different vectors. Ones aimed at getting and consume more and more, others at protecting what they already has, still others struggle for being a centers of regional power, and so on. As D. Smith pointed out, 'We are moving into an era where greed will no longer be the central force of our lives. The battle to get more will gradually be replaced by the fight to keep what you have, which will, in turn unless things change, gradually become a more basic struggle for survival. That struggle is already central for the poor. Sooner or later, some of the middle rich may join them in the same boat' [8, p. 349]. Therefore, a world of violent conflict everywhere is not the utopia. The hybrid wars and politically constructed conflicts have questioned the very notion of peaceful development of the global system. In sum, the period of relatively 'calm sun' is ended. The world enters in the times of forced redistribution of power and resources burdened by economic conflicts and confessional wars. Non-western mighty powers are questioned if not undemined the world social order established in XIX-XX centuries.

The current, i.e. transitional stage of the globalizing process is rather risky because of the absence of effective global political model (concept). We are at the peak of struggle of various global political models which are lack of ideas related to the means of diminishing of risks and enforcing of human rights and social justice. As D. Smith continued, there are at least two major reasons of instability of global system. 'One is the imperial impulse, whose 'purest' expression in modern times is not capitalist greed but politicized fear and anger expressed in fundamentalist drive to dominate or destroy. The other is the cosmopolitan condition, the anomic mixing of cultures and creeds filling the world's cities with crowd of displaced people searching for order, meaning and someone or something to blame for their discontent.' These trends 'interpenetrate in ways we do not yet fully understand' [9, p. 374-375].

Then, focus on what? Despite the current chorus of admiration related to the 'Asian mirade' (Singapore) it cannot obviously be the model of the 'Better World' since it is the island of the most powerful transnationals which could allow themselves such Garden-city oasis. In my view, the sociological focus should be first of all on those who suffered from misery, unemployment, and lack of vital services. Once again: our world not simply at risk, it is at the all-embracing risk. It cannot be removed immediately because it viruses are everywhere: in misery, terrorism as well as in the very logic of a consumer society, say, in unlimited appetites of transnationals, in the transformation of science from public good into 
economic good, etc. To my mind, the neoliberal approach to modeling of the 'better world' has some negative consequences. At least, it "has undermined the state and the public sphere; and it has fostered a political climate in which people under the age of 40 find it difficult to think beyond individualism. Meanwhile, the West is divided and becoming less dominant globally' [9, p. 374].

\section{The 'better world': For whom? And in what terms we should discuss its issues?}

Proceeding from the current state-of-arts, l'd state that there is no a single model of the 'better world.' Moving 'top-down', today, at least four countries or/and their clusters have their own vision of it (the US, Europe, China, the BRICS and some others). If one shifts to a regional level there will be much more ideas of 'better world'. Shifting, then, to the local level, we will find an endless list of wishes and demands. That is, a wishful thinking is not an adequate instrument for the building the models of the 'better future.' And finally: 'Who are "We"?', if we speak not about a sociological community but about the world population at large?

Next question: what is the time span (period) we should keep in mind speaking about the reach of the 'better future'? is this struggle has a 'point of destination' or it should be 'continuous' by its very nature? The commonly accepted way to answer these questions is to 'ascent from abstract to concrete' ( $\mathrm{K}$. Marks). But nowadays, in our very mobile and unpredictable world the process of clarification of the above tems should simultaneously move up and down, that is, topdown and bottom-up. Therefore, we should start this kind of theorizing 'here and now', because any future is deeply rooted in the past and the present. We cannot leave out that the very fact that the name of the coming the ISA Forum is indire ctly implicates that a model of 'the Better World' will be developed by the united forces of leading think tanks in the US and Europe.

One more question: what particular idea, concept or worldview on a 'global world' should be in the basement of this struggle? It seems to me that recently, one could observe the struggle of three main concepts: one-polar, be-polar and multi-polar world. The multi-polar is better, but the kind of relations between the stakeholders is an open question. What are the arguments (or preconditions) of those who maintains that the humanity is now capable to develop a unified worldview? In my view, it will lead us back to the times of actual world war. And finally, what kind of global social order (in the widest sense of the word) could be a precondition for the development of unified understanding of the 'better world' notion? After the WWII the global social order constructed by the countries -winners has been developed and adopted by the majority of the rest countries. But now it is clear that this order does not fit to the new world disposition of economic and political forces. And therefore, recently we are at the threshold of deep restructuring of this order.

Unfortunately, it has been the last but not the least question in this 'serial.' I have missed the very acute one: what the very word 'a struggle' means in this context? And who are the major actors of this struggle: countries, their clusters or people and their social movements? Or so called global financial elite? And finally, what is the character of this struggle: peaceful or violent? Which are the other forces which already involved or should be potentially involved in this process (for example, natural disasters or technical accidents)? Or, may be, a slow and silent degradation of total living environment is a social actor as well?

\section{World sociology on globalization: Is it actually exists? How to define a social capital in the era of globalization?}

In the last two decades, there were researches aimed at the revealing the ways of construction of a unified world sociology [10]. But today, to argue that this sociology already exists would be the overstatement. On the contrary, one could observe the tough struggle for the restructuring the whole institutional system of sociology. We must clearly acknowledge that today the US and European sociology are still the leaders in this realm of sociological thinking and modeling. This fact reflects the abovementioned disposition forces on the global arena. Nevertheless, within and beyond of the confines of this leading core there are sociological forces (theorists, research teams, networks, institutions) which are call for the development of more just and environmentally oriented concept of a 'global sociological body.'

Let us have a closer look on the topic. Once again: we see a variety of views and approaches. It may be a chaotic diversity of particular sociologies or the consolidated worldview on the main players on the sociological field. Nevertheless recently, any sociological work which analyzes a certain country or regional problem should consider them in the context of globalization processes. And vice versa: any work which analyzes the social and political activity of a particular actor (country, political party or social movement) must put this activity in the context of global processes (see, for example: [11; 12]). What kind of particular discourse is the key question here then? The emergence of a world web is a two-way traffic because it facilitates the communication between 'center' and 'periphery' in equal measure. Unfortunately nowadays, the dominating discourse is the struggle among a few world powers which pretend to play a leading role in the globalization process. But this inequality must be overcome: all sociologists as well as other social actors have a right to say.

As to a social capital, during last two decades there were a lot of discussions on how to define it. But how we should define a social capital in the era of globalization? There are two opposing views. The former stated that the consumer cosmopolitanism allows to world elite to gain the privileged status by the access to unique social capital needed in global society and by means of it to distance themselves from 'others' (read, 'losers' or 'wasted people'). That is, a privileged status is considered as social capital. The latter view, on the contrary, sees local communities and endemic cultures as an indispensable source of unique knowledge and know-how and which, above all, maintain the natural and social diversity of the global world. Therefore, the very process of modernization is considered not as disruptive in relation to the islands of endemic cultures but as a channel by means of which local cultures could be integrated into the globalization proces $s$ without losing its specificity. The headline question is acute in the direct sociological sense: do the existing division of 
sociological labor between so called theory-producing parent-state and data-providing periphery, i.e. ex-colonial one, is reasonable? Or the status of what we call a 'global sociology' should be reconsidered? If yes, it again readdresses us to the question of methodology of a North-South comparative research. By the way, what is the place in such division of the European East? And what is about the Greece, Portugal and some other member-states of the EU? We should keep in mind that a majority of textbooks defines sociology as a social science of modern industrial society and its after-effects. In my view, the actual social capital is that which is working in (or applicable to) a particular sociocultural milieu. Another aspect of the same problem is the relationships between professional and popular knowledge. The Wikipedia is internet analogue of this communication. There is no controversy between the 'great thinkers' and rank-and-file people. Conversely, they are needed each other, the method of crowd-sourcing has directly confirmed this statement.

\section{Impediments and priorities}

In my view, the corps of westem-oriented sociologists is somewhat guilty, because they very often see the rest world as a testing ground for their ideas and concepts. In particular, as M. Archer put it in her address to the participants of the ISA2010 Congress (Gothenburg, Sweden) titled 'The Current Crisis: The Silence of the Sociologists.' She stated that sociologists are guilty because they have collaborated in creating the context of the current crisis, firstly, by the promoting individualism in its models of the humanity and of agency. Secondly, these models cannot conceptualize any politicoeconomic philosophy resistant to unrestrained financialization. And thirdly, majority of social theorists cannot conceptualize a real civil economy and robust civil society (my record, $\mathrm{O}$. Yan). It is clear that prof. Archer spoke about the principles of so called Western sociology. Therefore, it seems to me that before the westem-oriented sociologists will begin to conceptualize the 'Better World' idea they should call in question its own basic moral and ethical princi ples.

As to priorities which should be moved forth on the global agenda, they are not clear still. Should all societies proceed along the path of peace? That is, to cease the fire in the most critical 'hot spots' and to compile a list of current agreements and disagreements between the adversaries? Or they must make every effort in order diminish the gap between rich and poor countries and by means of it to establish a new, more just social order? Or to map the list of common goals which are absolutely indispensable for the maintenance of the life on the planet including natural, socia and ethnical diversity? I agree with $\mathrm{M}$. Burawoy who called the sociologis ts to concentrate their attention on the processes of the degradation of social existence in a globalizing world. Burawoy wrote that 'the defense of society against third-wave marketization will have to be scaled up to the global level, but it must also universalize its reactive discourse: it will ha ve to embrace a discourse of human rights, which includes the restoration of labor and social rights. Human rights demand that humans treat each other as ends rather than means, that they potentially form a community of self-realization though symmetrical reciprocity and mutual recognition. It entails rights to dignified labor and rights to material comfort.' And he concluded: 'Third-wave marketization calls for a new political practice that joins disparate and desperate local defenses in the creation of a global civil society, cemented in the struggle for human rights in the quite specific context of their violation' [13, p. 358-359]. Modern Russian theorists draw our attention to the same contradiction but in the terms of man made nisk provoked by 'the coexistence of previously antagonistic values and cultures in one set time-space coordinates' $[14$, p. 65]. Finally, as theorists of global dynamics points out, the humanity is now at the beginning of the next revolution i.e. bio-technological one. Therefore once again, what should be a time horizon of our theoretical debates and construction ideas related to the 'Better World' idea?

\section{World sociology on globalization}

Methodologically, this process has never been characterized by unified discourse. On the contrary, this discourse has always been multisided and multidisciplinary. In my view, today the world global sociology at large is lag behind the real processes of globalizing processes. For example, it is openly seen that many 'global sociologists' use the method of 'global-local dichotomy' and pay not sufficient attention to the ongoing processes as the universalization of particularity and particularization of universality [15]. It is still unclear whether current globalization brings more gains or losses? In my view, its current trend is predominantly burdened by losses due to the new wave of tough struggle for deficit resources conducted by the USA, China and some other mighty world powers. Anyhow, there is no reason to interpret globalization as the new phase of modemization process. On the contrary, one could observe the multiplication of local and regional wars, pandemics and destruction of natural ecosystems. That is why methodologically, the future globalization studies should be both realistic in their field research and imaginative (C. R. Mills) in the realm of theorizing. Another question which needs more attention is the relationships between globalization as 'realpolitik' and cosmopolitanism as modal ethics. Though the latter notion deeply rooted in European culture, I am rather skeptical to cons ider this term as a working tool for globalization theorizing. I think that modern world is full of reverse trend, namely separatism and radical nationalism. Anyhow, while many western authors (U. Beck, A. Giddens, Kendall and some others) support the idea of 'reflexive cosmopolitanism' I think that the terms like 'ultimately utilitarian' or 'aggressive' cosmopolitanism are more fit to the cur rent phase of globalization.

As to the state-civil society relationships, it is now clear that the European model of welfare state is close to end as well as the concept of multiculturalism. This fact is openly recognized by the chancellor A. Merkel and other European leaders. Hence, the two more general questions follow: first, should we confine ourselves to the trends which dominate in the western societies and restrict ourselves by the westem mode of thinking? And the second: what is a master frame in which one should speculate on the 'better future': welfare state, control state, security state or monitoring state [16]? Or we should miss the question of the relationships between the statist and the global legal structures at all? I am far from the one-sided interpretation of the process in question. According to Schinkel, the state is both the patient and the docto $r$. It is in the hands of the state to introduce initiatives such as territorialization (as opposed to deterritorialization), uniformization (as opposed to pluralization) and reorganization (as opposed to differentiation) in order to redress its present situation. 
Schinkel concludes his book by saying that Foucault's work on governmentality could lay the theoretical foundation for such work' [17, p. 217]. Nevertheless, Ch. Rootes is right seeing the difference between the universal human rights and a particular type of citizenship [18].

The state-civil society relations have one more important dimension: the environmental one. The key question is what environmentalism means: the only 'a green shade' on social processes [19] or the basement of any 'Better World'? Let us have a brief look on leading theoretical approaches to this issue. First, the idea of 'sustainable development' moved forth in early 1980s failed. The reason is a double nature of a developmental process: every internal threat for such development is a logical continuation of a certain success. A set of international summits after the Stockholm summit (1992) gave nearly nothing in practical sense. Second, the new environmental paradigm $[20 ; 21 ; 22]$ is still remained as the idea without any successful attempts of its operationalization. The recent efforts of the International Social Science Council [23] has no political effect. As the fundamental survey conducted by C. Lever-Tracy showed the most sociologists around the world, outside the realm of environmental sociology, had little to say about ecologically induced possible social trajectories of world development. She underlined that since 1980s, there was a sharp decline of academic discussions on future scenarios and calls for 'a cooperative multidis ciplinarity of social and natural sciences working together' [24, p. 445]. Third, there are two major interpretations of our future from the environmental viewpoint. The former is stated that the misery in the so-called developing countries is the main threat to the Biosphere (the cutting of rainforests, etc.). The latter sees this threat in the uncontrolled invention in the realm of biotechnologies which sharply reduce the biodiversity of the Biosphere and therefore diminish its sustainability. Today, the major producers of the genetically-modified food are China, USA and Brazil. Four, recently the advanced methods of food production have become a powerful weapon (so called terminator biotechnologies). And five, it is clear now that there is a direct tie between wars, accumulation of capital, new herbicides invention and production of trans-genetic food-staffs. That is why the development of other branches of biotechnologies is under full control of powerful transnationals.

What is clear now can be summarized as follows: (1) today, there are no absolutely ecologically safe places on the Earth. There are the more or less safe/risky only; (2) globalization of all kinds of production and consumption means that the global community is transparent to all-embracing risks of any kind: social, technological, demographical, etc.; (3) the humanity continues to consider the Biosphere first of all as a resource store and not as a living space; (4) global environmental movement tumed into a set of national and intemational NGOs with a rather weak political influence. Some prominent environmental leaders were forced to associate themselves with quasi-liberal or left-wing political parliamentary parties. Or these leaders left the public sphere at all. The reasons of this withdrawing are well-known: lack of financial resources as well as of ideas and slogans which would be capable to mobilize ordinary people for protection of global environment. Though, the environmental problems aggravate in line with the globalization process; (5) $U$. Beck in his presidential lecture at the ISA sociological congress (2010) well defined the key opposition of this 'transitive' period: who will actually support any pro-ecological changes, which in many cases will undermine their own way of life and consumer standards? Or, in other words, in which way a cosmopolitan solidarity across any borders may become an actual 'greening community' which is an indispensable prerequisite of transnational policy of climatic changes restrain? And there a re two other methodologically important questions. First, in which the degree of climate changes will be the factor of global transformation of power and inequality? And second, in what measure these climate changes will promote the creation of cosmopolitan risk-societies which are now strongly separated socially and geographically? (my record, O. Yan.) What must be done right now? This question is urgent because it may be too late to have any impact on forces which produce the irreversible changes in our living environment.

\section{The current state of global social order and the importance of social movement studies}

The human community has now entered into a new phase of its state which I called the 'in-between'. But in contrast to the previous phase of globalization which has more or less definite vector, namely the shift 'from preindustrial toward industrial' type of a society, the current phase has no such definite vector. One part of world community is moving toward postindustrial model of living whereas the other part might be called as a movement of 'radical destroyers'. This kind of radicalism is a direct product of unjust and unequal world order and expansion of radicalism cannot be stopped by military operations, i.e. by sheer force only. In our mutually penetrating and highly interconnected world the language of weapons and bombarding is not sufficient. There is no other instrument of adjust of mutual understanding except dialogue. In turn, this dialogue is urgently needed in the development of multidisciplinary concept of such dialogue. Any form of brutal pressure (military, economic, by means of media) will lead to reverse results. The idea of meritocracy has not been realized. As a century ago the world order is based on military forces backed by mighty economy which in turn based on the access to resource sources around the world.

A permanently changing global context produces a rather explosive human material, i.e. the mass of people (more exactly, a mobile mob) which left their local or regional identity and didn't acquired a new one. It is the classical example of nomads with rather vague ideas concerning the 'Better World'. Politically and mentally it means the emergence of giant mass of poor people which is not on the 'margin of two cultures' (R. Park) but which is quickly has been transformed into 'new barbarians.' Or, more exactly, it is a negative by-product of globalization process. The events of the first decade of XXI century in the Near and the Middle East as well as in Mid-Asia clearly showed that so called emerging 'democratic social movements' (colored revolutions) have been only the mask of geopolitical plans and forces of major world stakeholders, be it states or corporations. It means that today the social movements are not the result of local and regional conflicts. Conversely, these movements are politically and economically constructed from above by the state or some international forces. On the one hand, in equatorial belt of states the social movements have often transformed into the armed troops. Nevertheless, I think that the development of grass roots initiatives and social movement like peace, justice and environmental movements across the world are of a high priority. 
The emerging of a new global order necessitates a detailed analysis of the response of yet not matured global social and economic institutions (both in its statist and civil components) to the challenges of barbarian radicalism. In my view, it is the key problem for sociologists and politicians. But the overwhelming majority of social movements are still reactive and not proactive. It is quite natural because today any forecast of world dynamics needs a substantial scientific and time resource. It is quite indicative that in recent times the difference between a street protest, police operation and the guerillas becomes less and less.

\section{Conclusion: Are the sociologists well prepared to develop a model of 'Better World'?}

The aim of this article has been to launch the decoding process of this rather general te m 'the Better World.' First, a sociological community is not sufficiently consolidated. There are at least four categories of researchers: professional sociologists, critical sociologists, public sociologists and policy ones [13, p. 353-358; 9, p. 375]. But their place and role in a society depend on the position of the particular society in the global societal system. Second, the still existing strong divide between 'central' and 'peripheral' social sciences should be gradually diminished. There is 'a cle ar predominance of the knowledge originating in the central countries, without proper validation in other places of the world' [25, p. 705]. This outcome has been confimed by the quantitative analys is of 30 years of production, collaboration and citations in social sciences. S. Mosbah-Natanson and Y. Gingras who confimed the 'center-periphery model and indicate that the centrality of the two major regions that are North America and Europe is largely unchallenged, despite the growing development of Asian social sciences.' Therefore, 'the dynamics of internationalization of social science research may... lead to a phagocytosis of the periphery into two major centers, which brings with it the danger of losing interest in the local objects specific to those peripheral countries.' Besides, it is indicative that internationally co-authored publications are more often cited whether self-citations have been declined [26, p. 639-640]. The hierarchy in the sociological field established by the western sociologists still remains. Currently, a new form of peripheriality has emerged: resistance of Russian, Asian and South African sociologists against a methodological domination of 'the developed West.' Third, sociology as an institution is still subject-like and not as problem-like structured. Networks within a particular discipline are much dense than between various disciplines. An interdisciplinary, problem-centered approach is still the pariah of this institution. The prevailing subject-like orientation of sociology both as the institution and social practice is a serious impediment for the building the 'better world' concepts and models. Four, global sociologists more interested in the analys is of the globalization trends of the particular disciplines than in the building scenarios and prospects of near and more distant future of the planet or/and its regions as whole entities. It is quite understandable because of unpredictable trends and reiterating emergence of 'unintended consequences.' Nevertheless, the attempts of local/regional/global monitoring and modeling should be a priority. Five, a more just and balanced relations (regime of competition) should be established between the sociologies of developed West and of developing Asia, Africa and the NIS. Today, 'excellence' has silently substitutes for 'quality'. As Vessuri et al. state, 'With the competition regime generated by citation-based indicators, the number of prize-winning scientists may increase, but the general quality of entire scientific community may stagnate, or even decrease (loss of vocations, loss of interest, etc.).' 'The evolutionary scenario .... will not work if the present competitive rules are not subverted and ultimately defused. The new nodes that could and should collaborate, from China to India, with Africa and South East Asia, will play the role of rebalancing world science and its communication system only if quality trumps excellence, if true collaboration comes before all-out competition. This means that the tools to create value must themselves be revaluated and rebuilt. In this regard, the social science has much to teach the natural sciences: this is also one of the unexpected and fruitful results of gradual convergence' between the sociologies of developed and developing countries $[27$, p. 649,660$]$. Six, if our efforts are aimed at the searching of a 'better world' they should be problem-based and action-oriented. That is why the whole corpus of literature on social movements is of a high importance (the classical example of such approach is the Alaine Touraine's and his like-minders work, [28]; see also: [29; 3]). As for me, a research process and public activity are two sides of the same coin. From the late 1980s onwards I am as a professional sociologist has regularly participated in public life in Russia and abroad (see: [30]). Therefore, the action-oriented sociology is the corner-stone of the 'better world' research, but in my view the very term of 'action' should be interpreted as a triple process: perception, comprehension (i.e. reflection) and action. More than that, silence of individuals and their communities should be considered as an indispensable moment of their individual reflection [31]. Seven, the heritage of sociological modeling of the past should not be neglected be it socio-historical analysis of the garden-cities theoretical models and projects, middle-range concepts of the green cities of tomorrow or grassroots attempts and their expertcitizens to better their local milieu. Once again: top-down and bottom-up approaches should be combined in every case. One should keep in mind that globalization has always been characterized by various socio-political discourses. But in our case the action-reflection discourse should prevail. And how to integrate in this mainstream the results of other discourses is still an open question. Eight, modern 'global sociologists' are mostly interested in comparative quantitative research and public opinion surveys of the international scale while the qualitative analys is of social knowledge produ ced by the NGOs is lag behind. In the run of empirical survey I had revealed five degrees of integration of a social researcher into the process of multidisciplinary study, from distanced to full-time integrated position [32]. A knowledge produced by local NGOs, in particular by the expert-citizens, is of a high value. Nine, this sociology should be an all-embracing, activistoriented, and space-time dynamic. Ten, one of the key notions of interdisciplinary approach is socio-ecological metabolism. That is, transformations caused by nature-socio-technical interactions. A sociologist should be simultaneously capable to conduct its own research and to interpret sociologically the data gained by naturalists and technicians and not to forget that any environment is a social actor as well. Eleven, this sociology have to be resource-oriented in the widest sense of the term. Twelve, the joint efforts of various researchers are needed for more deep investigation of the emergence of new social and political subjects in the run of globalization. And trust and solidarity action are indispensable preconditions of the construction of the 'better world.' 


\section{ISSN 2321-1091}

\section{Funding}

This work is part of the research project 'Sociology of critical conditions of urban ecosystems' supported by the Russian Humanitarian Scientific Fund (grant № 15-03-000-27).

\section{References}

[1] Schuerkens U., ed. (2004). Global Forces and Local Life-Worlds. Thousand Oaks, CA and New Delhi: Sage.

[2] Schuerkens U., ed. (2008). Globalization and Transformations of Local Socioeconomic Practices. London and New York: Routledge.

[3] Yanitsky O.N. (2015). Are the Sociologists Well Prepared to the Modern War? Journal of Social Sciences Research. 2015, Vol. 6 (3): 1990-1998. Available at: http://cirworld.com/journals/index.php/ jssr/article/view/3680/pdf 99

[4] Beck U. (1992). Risk Society. Toward a New Modernity. London: SAGE.

[5] Beck U. (1999). World Risk Society. Malden, MA: Polity Press.

[6] Yanitsky O. (2000). Russian Greens in a Risk Society. A Structural Analysis. Helsinki: Kikimora Publications.

[7] Yanitsky O. (2000a). Sustainability and Risk: The Case of Russia. Innovation: The European Journal of Social Sciences. Vol. 13 (3): 265-277.

[8] Smith D. (2008). Editorial: Beyond Greed, Fear and Anger. Current Sociology 56 (3): 347-350.

[9] Smith D. (2008). Globalization, Degradation and the Dynamics of Humiliation. Current Sociology 56 (3): $371-379$.

[10] Archer M. (1991). Sociology for one World: Unity and Diversity. International Sociology 6 (2): 131-148.

[11] Kaldor M., H. Anheier and M. Glasius, eds. (2003). Global Civil Society Yearbook. Oxford: Oxford University Press.

[12] Fraser M., ed. (2007). European Union: The Next Fifty Years. London: Financial Times Business.

[13] Burawoy M. (2008). What is to be Done? Theses on the Degradation of Social Existence in a Globalizing World. Current Sociology 56 (3): 351-59.

[14] Kravchenko S. and Salygin V. (2014). Slozhnye Opasnosti i Riski Sovremennogo Truboprovodnogo Transporta [Complex Dangers and Risks of Modern Mainline of Oil Transportation]. Sotsiologicheskaya Nauka i Sotsial'naya Praktica. 4(48): 50-66.

[15] Roberts on R. (1992). Globalization: Social Theory and Global Culture. London: Sage.

[16] Schinkel W., ed., (2009). Globalization and the State: Sociological Perspectives on the State of the State. Basingstoke: Palgrave Macmilan.

[17] Kosaka K. 2010. Review of book: Schinkel W., ed. (2009). Globalization and the State: Sociological Perspectives on the State of the State. Basingstoke: Palgrave Macmillan. Intemational Sociology Review of Books, 2010, Vol. 25, No 2, March: 216-219.

[18] Rootes C. (2008). The Globalization of Humanitarian Concern and the Emergence of 'Global Citizenships', available at: www.kent.ac.uk.sspssr/rootes.html

[19] Doyle T. and MacGregor S., eds. (2014). Environmental Movements around the World. Shades of Green in Politics and Culture. Santa Barbara, Calif.: Praeger.

[20] Catton W. R., Jr., and Dunlap R. (1978). Environmental Sociology: A New Paradigm. American Sociologist. Vol. 13: $41-49$.

[21] Catton W.R., Jr. and Dunlap R. (1980). A New Ecological Paradigm for Post-Exuberant Sociology, American Behavioral Scientist, Vol. 24, No 1:15-47.

[22] Milbrath L. (1984). Environmentalists: Vanguard for a New Society. Albany: State University of New York Press.

[23] The World Social Science Report. Changing Global Environments (2013). Paris: UNESCO.

[24] Lever-Tracy C. (2008). Global Warming and Sociology. Current Sociology. 56 (3): 445-466.

[25] Zincke C. (2014). Local and Global communication in Chilean Social Science: Inequality and Relative Autonomy. Current Sociology 62 (5): 704-722.

[26] Mosbah-Natanson S. and Gingars I. (2014). The Globalization of Social Sciences? Evidence from a Quantitative Analysis of 30 years of Production, Collaboration and Citations in the Social Science (1980-2009). Current Sociology 62 (5): 626-646.

[27] Vessuri H., Guedon J.-C., Cetto A. (2014). Excellence of Quality? Impact of the current Competition Rregime on Science and Scientific Publishing in Latin America and its Implications for Development. Current Sociology 62 (5): 647-665. 


\section{ISSN 2321-1091}

[28] Touraine A., Dubet F., Hegedus Z., Wieviorka M. (1983). Anti-nuclear Protest. The Opposition to Nuclear Energy in France. Cambridge: Cambridge University Press.

[29] Morris A. and C. Mueller, eds. (1992). Frontiers in Social Movement Theory. London: Yale University Press.

[30] Deelstra T. and O. Yanitsky, eds. (1991). Cities of Europe: The Public's Role in Shaping the Urban Environment. Moscow: Mezhdunarudnye Otnosheniya Publishers.

[31] Naumova N. (2006). Chelovek i modernizatsiya v Rossii [Man and modemization in Russia]. Moskva: Kanon+, ROOI.

[32] Yanitsky O. (2005). Dialogue between Science and Society. Social Sciences. A Quarterly Journal of the Russian Acad. of Sciences Vol. 36 (2): 78-90.

\section{Authors' Biography}

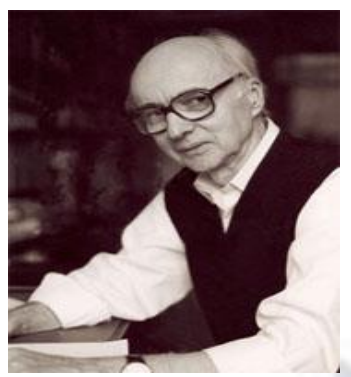

Yanitsky Oleg Nikolaevich is a professor and the head of the department of socio-ecological research at the Institute of sociology of Russian academy of sciences. His research topics are environmental politics and social movements, environmental and man-made catastrophes, risk and biographical research. He wrote 15 books (four in English) and about 300 articles in Russian and English. From 1982 onwards, he published the articles in the Intemational social science journal, International sociology, the International Sociology review of books, Current sociology, Innovation and in some others. He was the participant of the UNESCO's 'Man and the Biosphere' program (1976-91), and 'The World social science report' in 2012-13. Avocations: oil painting, collecting oral life histories. 